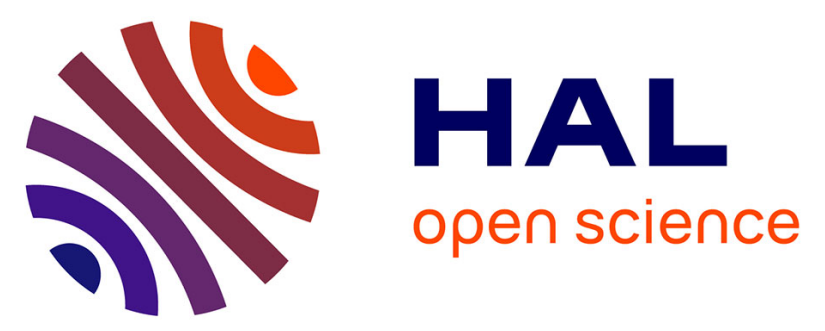

\title{
MULTI-SENSOR DATA FUSION FOR IDENTIFYING MALARIA ENVIRONMENTAL FEATURES
}

Zhichao Li, Thibault Catry, Nadine Dessay, Emmanuel Roux, Etienne Mahé, F. Seyler

\section{- To cite this version:}

Zhichao Li, Thibault Catry, Nadine Dessay, Emmanuel Roux, Etienne Mahé, et al.. MULTI-SENSOR DATA FUSION FOR IDENTIFYING MALARIA ENVIRONMENTAL FEATURES. IGARSS 2016

- 2016 IEEE International Geoscience and Remote Sensing Symposium, Jul 2016, Beijing, China. 10.1109/IGARSS.2016.7729653 . hal-01829725

\section{HAL Id: hal-01829725 \\ https://hal.science/hal-01829725}

Submitted on 4 Jul 2018

HAL is a multi-disciplinary open access archive for the deposit and dissemination of scientific research documents, whether they are published or not. The documents may come from teaching and research institutions in France or abroad, or from public or private research centers.
L'archive ouverte pluridisciplinaire HAL, est destinée au dépôt et à la diffusion de documents scientifiques de niveau recherche, publiés ou non, émanant des établissements d'enseignement et de recherche français ou étrangers, des laboratoires publics ou privés. 


\title{
MULTI-SENSOR DATA FUSION FOR IDENTIFYING MALARIA ENVIRONMENTAL FEATURES
}

\author{
Zhichao Li ${ }^{1}{ }^{*}$, Thibault Catry ${ }^{I}$, Nadine Dessay ${ }^{I}$, Emmanuel Roux ${ }^{1}$, Etienne Mahé ${ }^{I}$, Frédérique Seyler ${ }^{1}$ \\ ${ }^{1}$ ESPACE-DEV, UMR 228 IRD/UM/UR/UG, Institut de Recherche pour le Développement (IRD), \\ Montpellier, France \\ zhichao.li@teledetection.fr; thibault.catry@ird.fr; \\ nadine.dessay@ird.fr; emmanuel.roux@ird.fr; etienne.mahe@ird.fr; frederique.seyler@ird.fr
}

\begin{abstract}
Malaria remains a persistent health problem in the crossborder area between French Guiana and Brazil. Various factors like environmental changes, population movements, etc. significantly influence the malaria transmission. In such context, optical and SAR data were used for producing a precise land cover map, including the resting and breeding sites of malaria vectors and human habitats. This study is a foundation for quantifying the degree of exposure of human populations to malaria vectors and thus for estimating and monitoring the malaria transmission risk.
\end{abstract}

Index Terms - Multi-sensor, optical and SAR, classification, remote sensing, malaria

\section{INTRODUCTION}

Malaria mostly covers tropical and subtropical zones, with an estimated 214 million new cases and 438,000 deaths in 2015 [1]. In the Americas, the Amazonian region is the most affected by the disease. Movement of malaria across international borders poses a major obstacle for malaria elimination due to various human activities, population movement, human vulnerability due to limited formal education and few financial resources, inadequate health systems, etc. [2]. Natural and human-made ecosystem changes, such as climatic perturbation and land use and land cover (LULC) changes, can affect significantly the distribution of malaria by making disease vector (anopheles darlingi mosquito) habitats more or less suitable [3-4].

Using remote sensing is a pertinent tool that can characterize almost completely and continuously the environment related to malaria transmission on both sides of the international border. Stefani et al. (2013) did a systematic review of literature showing that many studies in the Amazon successfully used optical data for accessing the different land cover types related to malaria and analyzed their relationship with entomological and / or epidemiological data [3]. However, the identification of wetland types (vegetated or not, persistent water, temporarily flooded areas, etc.) considered as main resting and/or breeding sites for malaria vectors, is a formidable challenge due to dense vegetation cover in tropical areas. Lband Synthetic aperture radar (SAR) imagery has the capability to penetrate such barrier and is sensible to the variation of soil moisture and water level, which could provide more detailed information about wetlands. Thus, the integration of optical and SAR data is a suitable solution for the production of a precise land cover map related to malaria transmission.

The objective of this study is to identify the different LULC types related to malaria transmission combining optical and SAR data.

\section{STUDY AREA}

The Franco-Brazilian cross-border region considered here is composed by the French municipalities of Camopi, SaintGeorges-de-l'Oyapock and Ouanary, which are located on the western bank of the Oyapock River, and the Brazilian municipality of Oiapoque on the eastern bank of the river (Figure 1). Human habitats are mainly located in SaintGeorges (FR), Oiapoque (BR) and the villages of Camopi (FR) (see the red rectangles in Figure1).

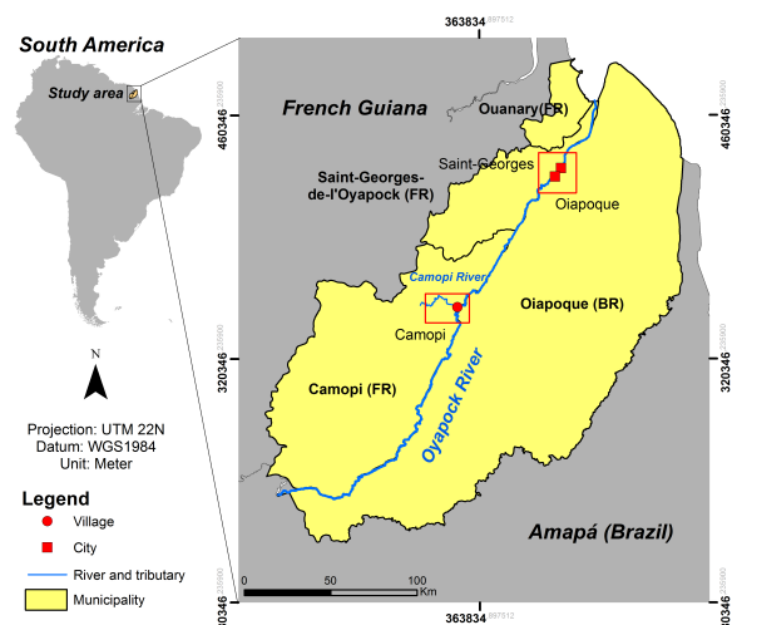

Figure 1: Map of cross-border region between French Guiana and Brazil. 


\section{DATA AND METHOD}

\subsection{LULC types and dataset}

The LULC types related to malaria transmission in study area were visually identified using the review of Stefani et al. (2013), aerial images (BD-ORTHO®IGN, 50 $\mathrm{cm}, 2006$ ) and one archive PALSAR image (Table 1). Forest and flooded forest are usually identified as resting site of adult vectors [3-4]. Free water, flooded forest and swamps can provide potential larval habitats [3]. The optical and SAR data used in this study cover the two major areas of human presences: Saint-Georges and Oiapoque.

Table 1: LULC types and data used in this study

\begin{tabular}{lc}
\hline \multicolumn{1}{c}{ LULC types } & Data/Sensors \\
\hline Bare soil / built-up / road & \\
Forest & SPOT 5 (10 m) \\
Medium vegetation & Multispectral (MS) \\
Herbaceous vegetation & $(2012 / 10 / 14)$ \\
Slash-and-burn / asphalt & (Dry season) \\
Free Water & \\
\hline Bare soil & \\
Flooded forest & PALSAR (12.5 m) \\
Forest & (L-band, 2010/10) \\
Free Water & (Dry season) \\
Swamps & \\
\hline
\end{tabular}

\subsection{Pixel class attribution of optical-SAR classifications}

\subsubsection{Pretreatments of optical and SAR data}

One SPOT 5 image was acquired at $1 \mathrm{~A}$ level in which radiometric calibration and orthorectification have been successively performed by using the ENVI 5.1. For the PALSAR image acquired at level 1.5 in which radiometric calibration, geometrical correction and speckle filtering (Lee filter $3 * 3$ ) have already been performed by Japanese Space Agency (JAXA).

\subsubsection{Multi-sensor classifications}

Several spectral indices were calculated from the pretreated SPOT 5 MS image (Table 2). A decision tree-based classification was then carried out for mapping the various LULC types using ENVI 5.1 (Figure 2).

Table 2: Spectral indices derived from SPOT 5 image

\begin{tabular}{lc}
\hline \multicolumn{1}{c}{ Index } & Formula \\
\hline Normalized Humidity Index (NHI) & $($ SWIR-G) / \\
Normalized Difference Water Index & $($ SWIR+G) \\
(NDWI2) & $($ G+NIR) $)$ \\
Normalized Difference Vegetation & $($ NIR-R)/ \\
Index (NDVI) & $($ NIR+R) \\
\hline
\end{tabular}

Normalized Difference soil Index (NDSI)

Ratio vegetation index (RVI)

$(\mathrm{R}-\mathrm{G}) /(\mathrm{R}+\mathrm{G})$

G: green; R: red; NIR: near infrared; SWIR: short wave infrared

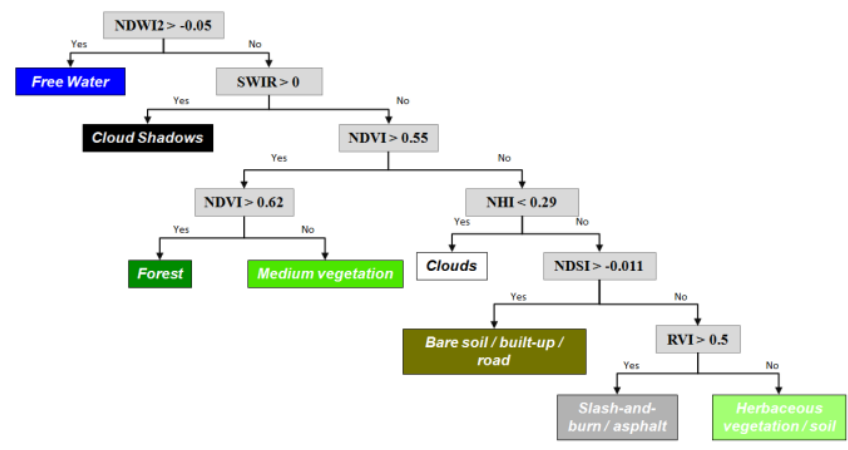

Figure 2: Classification decision tree. Decision tree nodes are in grey.

The resulting classification was post-processed using the majority analysis (kernel size $3 * 3$ ) for removing the isolated pixels. Finally, we evaluated the classification by randomly choosing 20 sites in each class and establishing the actual land cover of these sites by photo-interpretations of one Pleiades image dated September 30, 2012 with a 50centimeter spatial resolution.

A textural analysis (GLCM under Sentinel tool box) was performed and a simple thresholding method on the variance of PALSAR signal and a colored composition (Red $=\mathrm{VH}$, Green $=\mathrm{VV}$, Blue $=\mathrm{VH} / \mathrm{VV}$ ) was then used for extracting bare soil, flooded forest, forest, free water and swamps.

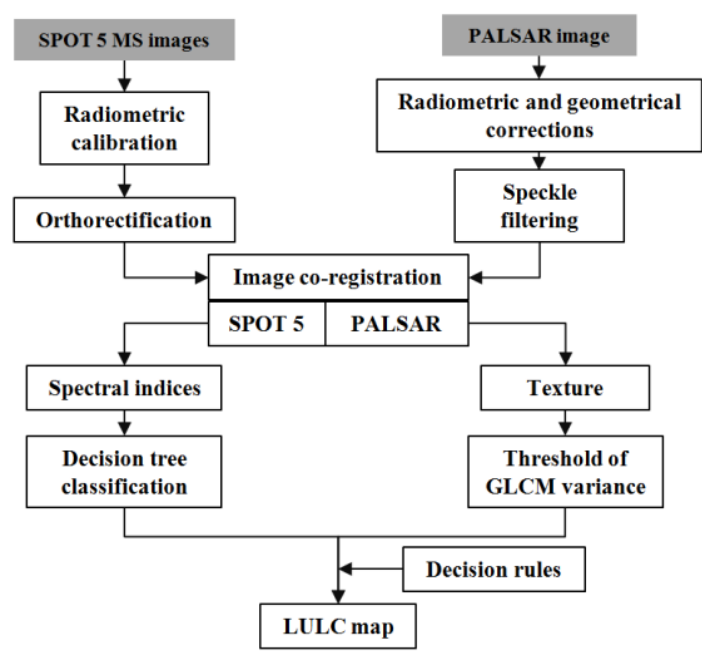

Figure 3: Summarized method of optical-SAR classification fusion for mapping the malaria environmental features.

\subsubsection{Decision level fusion of classifications}


Combining the information from SPOT 5 and PALSAR data using the knowledge-based decision rules: 1) If a pixel belongs to PALSAR free water or SPOT 5 free water, then the pixel is labelled as free water; 2) If a pixel belongs to PALSAR bare soil or SPOT 5 bare soil/built-up/road, then the pixel is labelled as bare soil/built-up/road; 3) If a pixel belongs to one of PALSAR wetlands classes and SPOT 5 vegetation class, then the pixel is labelled as wetland. The overview of method is presented in Figure 3.

\section{RESULTS AND DISCUSSION}

\subsection{Results}

Figure 4 showed the resulting SPOT 5 classification. The overall accuracy was found to be 0.90 and the kappa coefficient was 0.84 .

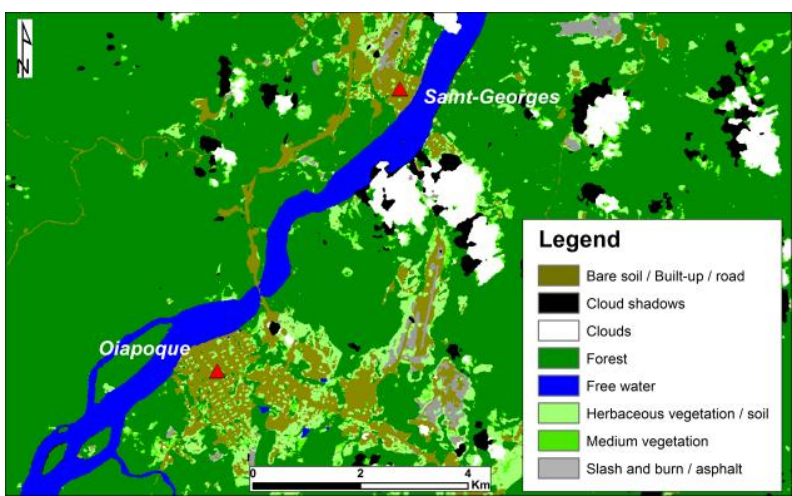

Figure 4: Pixel-based land cover map of SPOT 5 image in the region of Saint-Georges and Oiapoque.

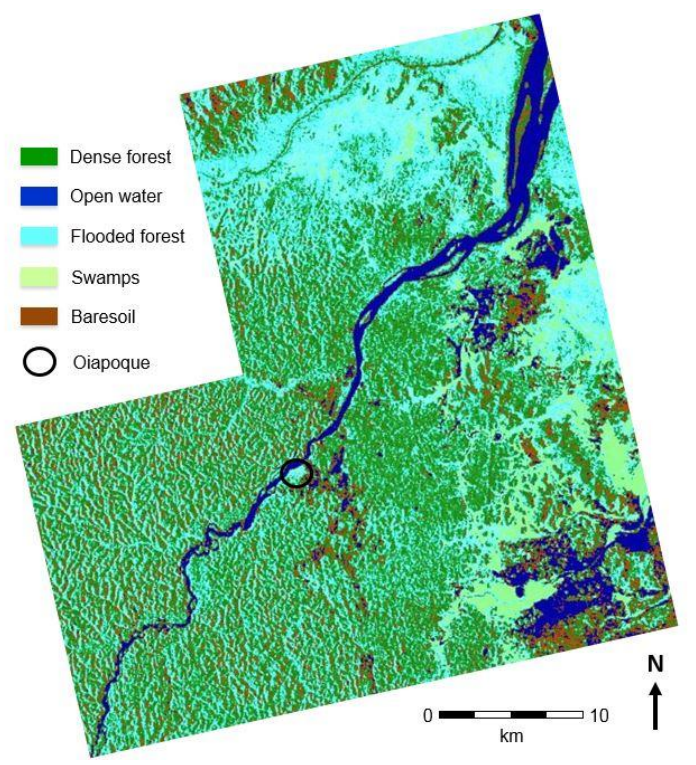

Figure 5: Wetlands land cover map extracted from PALSAR image in the region of Saint-Georges and Oiapoque.
Comparing with the SPOT 5 classification, this method allowed us to characterize free water, flooded forest and swamps (Figure 5) using an archive 2010 image. Moreover, it is important to remind that we used free archive PALSAR imagery in order to test the contribution of L-band SAR data to the identification of malaria environmental features, before considering the acquisition of expensive new L-band data.

The validation of PALSAR classification is complicated but some insights could be obtained from 2010 archive optical imagery if the cloud cover is not too dense. Recent field surveys during the similar period (similar season) can also be used for the validation since the identified wetlands are not strongly changed with time.

Figure 6 shows the various types of wetlands identified in the study area during a field survey conducted in 2015 where open waters (rivers A and ponds B), and various types of swamps (C and D) more or less densely covered by surface vegetation. L-band SAR (here $12.5 \mathrm{~m}$ resolution PALSAR data) is an efficient tool for the detection of large wetlands, which can define main resting, and breeding sites of malaria vectors.

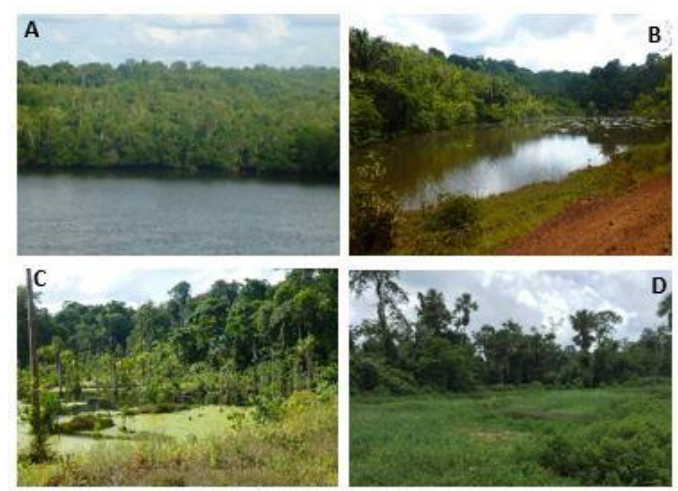

Figure 6: Various types of wetlands identified in region of Saint-Georges and Oiapoque.

\subsection{Discussion}

This study shows that fusion of land cover layers extracted from optical and SAR high-resolution imagery is an efficient tool for detecting large permanent (or long-lasting) wetlands (potential breeding sites) and various forest types (potential resting and feeding sites). Land cover classification of SPOT 5 image suffers two mains flaws: the impossibility to penetrate the forest canopy and disturbance from persistent cloud cover in tropical areas. In particular, L-band SAR has proven its ability to detect the water under forest, a key element for the identification of breeding sites of malaria vectors and malaria vector control.

Until now, only free archive SAR data were used in order to test the methodology but the acquisition of PALSAR 2 data is planned. Its main advantage is the possibility to access very high spatial resolution. Combining 
very high resolution optical (SPOT 6-7 / Pleiades) together with the very high resolution SAR permit characterize the urban structures (Figure 7) and minor sizes, non-permanent water bodies such as domestic wetlands within the urban areas, at the direct contact with vulnerable populations.

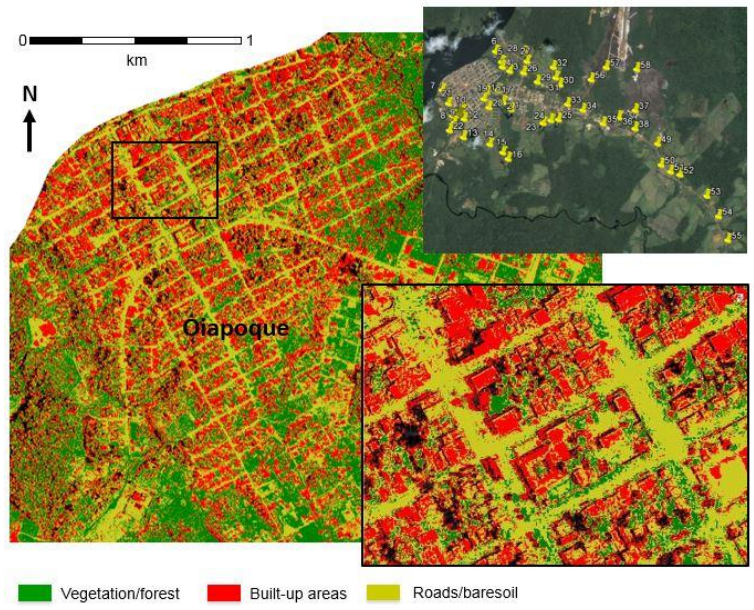

Figure 7: Pixel-based land cover map based on aerial images of 2006 and the domestic (observed and potential) wetlands within urban area (Google Earth background) in Oiapoque.

These results of land cover classification fusion from optical and SAR data are the basis of a landscape-based model of malaria transmission risk (Figure 8) [4].

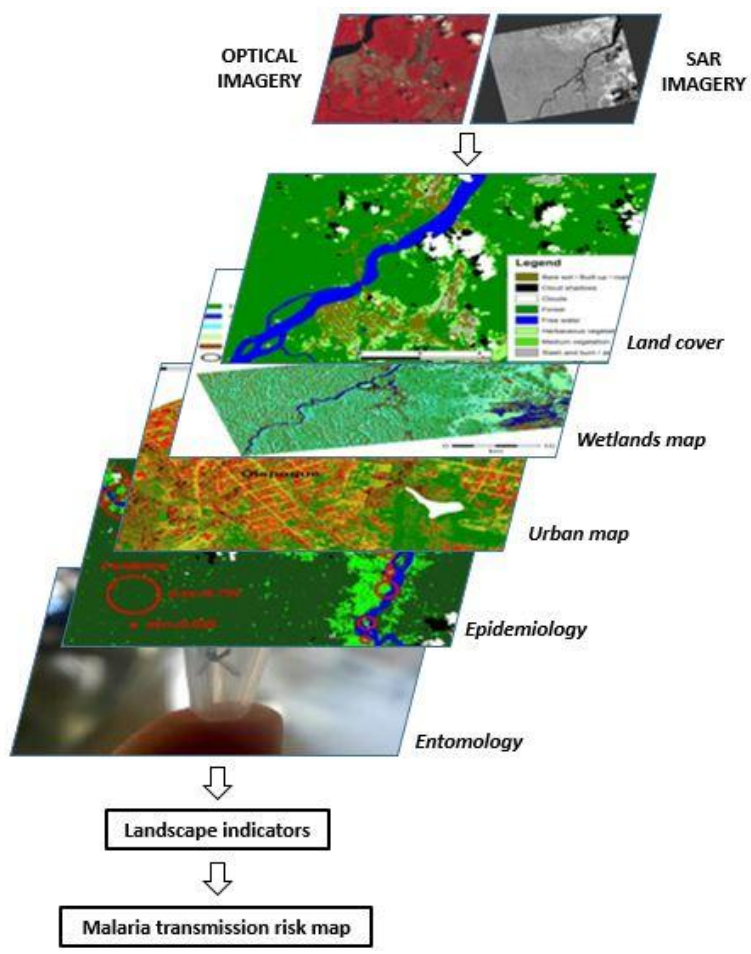

Figure 8: Landscape-based model of malaria transmission risk involving the decision-level fusion of spatialized information layers [4].
The layers of forest / vegetation and wetland types, are then combined to a layer of urban classification and 2 fieldbased layers: one regarding the entomology of mosquitoes and the malaria epidemiology in the area. These combined layers allow the calculation of landscape indicators and consequently the creation of malaria transmission risk map integration vector-related environmental information (hazard estimation) and human related environmental factors (vulnerability assessment).

\section{CONCLUSION AND PROSPECTS}

This study provides a method of identification of environmental features associated with malaria vector resting and breeding sites. Optical and SAR remote sensing have been proved to be complementary for this purpose. This method provides the complete LULC information about malaria transmission, which may be automatically and easily reproduced at temporal scale using a time series of images. The fusion of layers containing spatialized information extracted from optical and SAR data from various sensors and at various resolutions aims at producing indicators and malaria transmission hazard/risk maps to support decision-making processes by local institutions /authorities and public health actors.

\section{ACKNOWLEDGMENTS}

This research was supported by the TéléPal project (CNESTOSCA 2014 call), the Biodiva program funded by GUYAMAZON action (IRD, MAEDI, Brazilian FAPs), the GAPAM-Sentinela project (Guyamazon call) and the China Scholarship Council.

\section{REFERENCES}

[1] WHO. "World Malaria Report 2015", World Health Organization, Geneva, Switzerland, 2015.

[2] K. Wangdi, M.L. Gatton, G.C. Kelly, A.CA. Clements, "Cross-border Malaria: A Major Obstacle for Malaria Elimination," Advances in Parasitology., vol. 89, pp. 79-107, 2015.

[3] A. Stefani, I. Dusfour, A.P.S.A. Corrêa, M.C.B. Cruz, N. Dessay, A.K.R. Galardo, C.D. Galardo, R, Girod, M.S.M. Gomes, H. Gurgel, A.C.F. Lima, E.S. Moreno, L. Musset, M. Nacher, A.C.S. Soares, B. Carme, E. Roux. "Land cover, land use and malaria in the Amazon: a systematic literature review of studies using remotely sensed data," Malaria Journal., vol. 12, pp.192-200, 2013.

[4] Z. Li, E. Roux, N. Dessay, R. Girod, A. Stefani, M. Nacher, A. Moiret, F. Seyler, "Mapping a Knowledge-Based Malaria Hazard Index Related to Landscape Using Remote Sensing: Application to the Cross-Border Area between French Guiana and Brazil," Remote Sens., vol. 8, pp. 319, 2016. 